\title{
BMJ Open Determinants of childhood morbidity in Bangladesh: evidence from the Demographic and Health Survey 2011
}

\author{
Md Moustafa Kamal, ${ }^{1}$ Md Masud Hasan, ${ }^{2}$ Rachel Davey ${ }^{1}$
}

To cite: Kamal MM, Hasan MM, Davey R. Determinants of childhood morbidity in Bangladesh: evidence from the Demographic and Health Survey 2011. BMJ Open 2015;5:e007538. doi:10.1136/bmjopen-2014007538

- Prepublication history for this paper is available online. To view these files please visit the journal online (http://dx.doi.org/10.1136/ bmjopen-2014-007538).

Received 8 January 2015 Revised 4 August 2015 Accepted 14 August 2015

\section{CrossMark}

${ }^{1}$ Centre for Research and Action in Public Health, Health Research Institute, University of Canberra, Bruce, Australian Capital Territory, Australia

${ }^{2}$ Fenner School of Environment and society, Australian National University, Canberra, Australian Capital Territory, Australia

Correspondence to Md Moustafa Kamal; moustafa.kamal@anu.edu.au

\section{ABSTRACT}

Objectives: The present study aims to estimate the incidence of preventable infectious diseases or associated symptoms among young children in Bangladesh and also determine the factors affecting these conditions. The study hypothesised that various background characteristics of children as well as their parents influence the incidence of morbidity of children aged below 5 years.

Setting: The study used data from the most recent nationally representative cross-sectional Bangladesh Demographic and Health Survey (BDHS) conducted in 2011.

Participants: A total of 7550 children aged below 5 years during the survey from mothers aged between 12 and 49 years are the participants of the study.

Results: In general, younger children were more likely to suffer from multiple health conditions than their older counterparts. Children belonging to households classified as poor $(\mathrm{OR}=1.425,95 \% \mathrm{Cl}(1.130$ to 1.796)) or middle ( $\mathrm{OR}=1.349,95 \% \mathrm{Cl}(1.113$ to 1.636)) faced greater risk of illness than those from well-off households. A combination of source and treatment practices of drinking water showed a significant impact on incidence of childhood morbidity. Children from households using untreated non-piped water were $85.8 \%(\mathrm{OR}=1.860,95 \% \mathrm{Cl}(1.269$ to 2.728)) more likely to suffer from comorbidity than those who treat their piped drinking water. However, we observed that water treatment alone has no impact unless the water itself was sourced from a pipe.

Conclusions: Accelerated programmes promoting access to safe drinking water along with water treatment practices, and better household environment may prove effective in reducing the incidence of childhood morbidity in Bangladesh.

\section{INTRODUCTION}

Diarrhoea and acute respiratory infection (ARI) with their associated symptoms such as fever, cough and difficulty in breathing are among the most common forms of childhood morbidity which lead to millions of deaths worldwide each year. No statistics are available on deaths resulting from fever alone; however, in 2010, diarrhoea and ARI

\section{Strengths and limitations of this study}

- The data used for the research is one of the largest and most recent nationally representative surveys in the country.

- Unlike most other previous studies in the country and elsewhere, this study focuses not just on individual conditions but also on comorbidity.

- Given the cross-sectional nature of the data used for the study, seasonal variations in disease episodes are not fully accounted for.

- Data from 2011 have been used, but there may have been changes since this date in childhood morbidity.

- Estimates on the incidence of morbidity were also based on self-reported responses of mothers.

as a condition accounted for about $22 \%$ of the estimated 7.6 million child deaths globally. ${ }^{1}{ }^{2}$ In addition to mortality, morbidity hinders normal physical growth during childhood, resulting in a higher prevalence of poor nutrition. ${ }^{3}{ }^{4}$ Although Bangladesh has the highest life expectancy and the lowest infant and under five mortality rates in the South Asian region, the incidence of childhood morbidity is still alarming. ${ }^{25}$

In developing countries, the exposure and response to diseases are conditioned by a multitude of factors associated with the background of children themselves, their parents and the household environment in which they grow up. ${ }^{6}$ For instance, risks of ARI and diarrhoea were found to vary by age of children, with younger children experiencing a higher likelihood of these conditions than their older counterparts ${ }^{7} 8$ for ARI in Bangladesh and Iraq, respectively, ${ }^{9}{ }^{10}$ and seven for diarrhoea in the Democratic Republic of Congo (DRC), Egypt and Ethiopia, respectively. In Bangladesh, male children generally tend to get preferences in terms of better food, healthcare and treatment facilities, which results in morbidity 
differentials between male and female children. ${ }^{11-13}$ In Bangladesh and Egypt, urban children receive better health facilities than those who reside in rural areas and consequently are less likely to suffer from infectious diseases. Regional differentials (administrative division) on childhood morbidity in Bangladesh were also observed in previously published studies. ${ }^{814}$

Parental educational status is observed as a key determining factor in childhood morbidity in developing countries. ${ }^{10}$ In Nigeria, children of educated mothers were found to have a lower risk of diarrhoea even if they lived in poor households. ${ }^{15}$ Educational attainment of both parents and access to mass media of mother were observed as significant predictors of child morbidity in Bangladesh and elsewhere. ${ }^{16}{ }^{17} \mathrm{~A}$ number of nongovernmental microcredit organisations provide soft loans and run awareness programmes for marginalised poor women in Bangladesh. The membership status of mothers in such organisations has a positive impact on the health and morbidity of their children; however, their effectiveness in reducing childhood morbidity is not obvious. ${ }^{13} 18$

Numerous studies from developing countries have shown that the incidence of diarrhoea varied according to the type of toilet facility used by the households. ${ }^{7} 1019$ A similar relationship was observed in the slum areas of Bangladesh's national capital, Dhaka, where the use of an improved water source and improved sanitation had a significant impact on the incidence of childhood diarrhoea. ${ }^{16}$ A study from Nepal concluded that children exposed to passive smoking had a positive but statistically insignificant risk of developing ARI compared with nonpassive smokers. ${ }^{20}$ Type of cooking fuels, location of kitchen and household members' smoking habit were important factors for ARI in Bangladesh. $^{21}$ In Bangladesh, household's economic affluence showed a significant impact on morbidity of the children. ${ }^{7}$ Crowding index, as measured by the number of persons living per room, also showed an association on the exposure to diarrhoea. ${ }^{10}$

One of the main limitations of these studies is that, almost always, the studies are exclusively focused on predicting factors associated with a single health condition despite the fact that children in low and middle income countries most often suffer from multiple health problems arising from limited access to health services and a poor household socioeconomic environment in these countries. Hence, in this paper, we specifically focus on comorbidity among young children so that the government of Bangladesh and interested parties are able to use the evidence to design and implement programmes that address exposure to multiple illnesses in the country.

\section{METHOD}

The paper uses data from the nationally representative, cross-sectional Bangladesh Demographic and Health survey (BDHS) conducted in 2011. BDHS consists of a sample of households obtained through a two-stage stratified sampling procedure. ${ }^{22}$ In the first stage, the country was divided into 20 strata and a sample of 600 Enumeration Areas (EAs, those which are considered as the Primary Sampling Units) were selected independently from each stratum using probability proportional to the size technique as shown in figure 1 . In the second stage, an equal probability systematic sampling technique was employed to select 30 households from each of these EAs. Finally, ever-married women aged between 12 and 49 years living in the selected households were approached for interview. This study uses information from 7550 children under the age of 5 years born to women living in these households.

The morbidity data contained in the survey come from the mother's responses to questions on recent episodes of various forms of morbidity. Mothers were asked if their child had fever, cough, short rapid breaths or diarrhoea in the 2 weeks preceding the survey. Combining the diseases into one variable is a challenging task as all the diseases do not share the same set of risk factors. One way to manage the issue is to categorise the data into single disease and also their various combinations. However, modelling variables with a large number of categories introduces more complexity and uncertainties in estimating parameters. Therefore, this study considered a more balanced way by dividing the morbidity variable into three mutually exclusive and collectively exhaustive categories: as those experiencing 'no condition', only 'one condition' and 'multiple

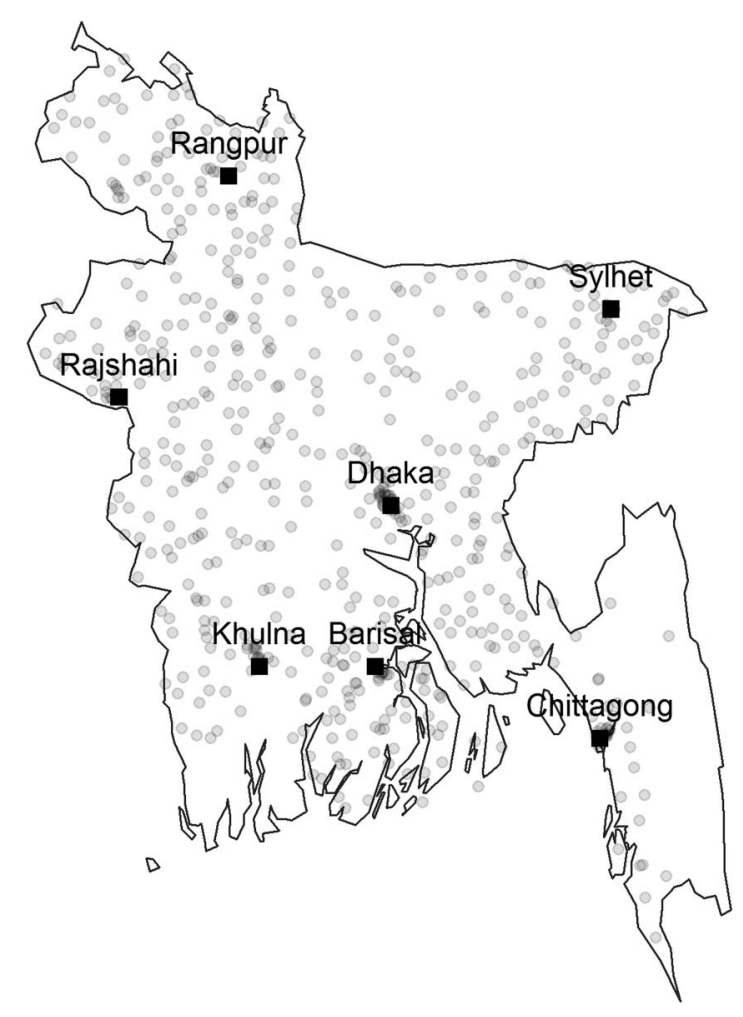

Figure 1 Distribution of enumerated areas selected in the sample (grey dot points). 
conditions'. This approach may consider the severity of the disease and also reduce the parameter uncertainty in fitting models.

Choice of relevant factors associated with incidence of childhood morbidity was guided by previous research and the researchers' own knowledge of the study area. ${ }^{6-21}$ Most of the variables used in the analysis were based on the original coding. However, a number of variables were obtained as a combination of two or more variables, or by regrouping the levels of individual variables, as discussed below.

Although more than 700 non-government microcredit organisations, including the Grameen Bank, founded by Nobel laureate Muhammad Younis, work in Bangladesh, only a few have a significant number of clients. In this study, we considered the major five (Grameen Bank, ASA, PROSHIKA, BRAAC and BRDB) and mothers were categorised into those who are or are not members of any of these organisations. Mothers were also categorised as those who have (1) or do not have (0) access to any electronic media (radio or television). The variable, toilet facility, was created with various combinations of type of facility (no facility, not improved and improved) and sharing status (shared and not shared). Similarly, the source of drinking water was created with the source (piped and not piped) and treatment practice (treated and not treated) of drinking water. Type of cooking fuels was categorised as cleaners (Biogas, Natural gas, LPG and electricity) and non-cleaners (otherwise).

The BDHS 2011 data contain an indicator of household wealth status constructed by combining variables related to ownership of household items (ie, televisions and bicycles), dwelling characteristics (source of drinking water, sanitation facilities) and construction materials of the unit in which the household lives. ${ }^{22}$ However, the impacts of source of drinking water and type of toilet facility on child morbidity were assessed separately. Hence, to capture the effects of wealth status on morbidity, a new wealth index was created by removing these variables. Thus, a new wealth index restricted the set of items: namely, household possessions (mobile, electricity, radio, television, motorcycles, refrigerator, autobike and autorickshaw), total number of households sharing a water source, location of source of water supply and construction materials (such as floor, roof and wall). Moreover, using the principal component score (created using the aforementioned variables), the households were categorised as poor (lower $31.5 \%$ ), middle $(52.9 \%$ ) and rich (upper 15.6\%) that reflect the of current poor-middle-rich ratios of the country. ${ }^{23}$

All in all, 19 variables were captured in the present analysis. Except for the number of people sharing a room and age of the mother at the birth of the child, all explanatory variables were used as categorical. Independent variables with levels and percentage distributions are presented in table 1 . In exploring the association between these variables and the incidence of childhood diseases, both bivariate and multivariate approaches were pursued. The multivariate analysis was performed using multinomial logistic regression, a model which is most appropriate for a polytomousdependent variable ${ }^{24}$ in a multivariate setting. Analysis on the data was performed using SPSS and R.

\section{RESULTS}

Results shown in table 1 suggest that $45.7 \%$ of children in Bangladesh experienced at least one episode of ill health in the 2-week period prior to the Survey. This is significantly lower than was observed 5 years previously $(49.7 \%)$, suggesting an improvement in the health status of children in the country. ${ }^{22}$ The results and the associated $\chi^{2}$ tests shown in the table reveal that the incidence of child morbidity in Bangladesh is significantly associated with age of the child, household wealth status, the educational background of both parents and region and place of residence. Access to improved toilet facility, source of water supply and water treatment practices have also shown a strong association with childhood morbidity status. On the contrary, sex of the child, presence of other children in the household and smoking in the household precinct seemed to have no impact on the incidence of child morbidity in the country. Mother's decision-making roles showed a significant impact on child morbidity but in an unexpected direction. As mentioned earlier, the mothers are the primary carers of Bangladeshi children. Hence, the variable was also considered in the multivariate setting. The other variables were excluded from further consideration.

Table 2 shows ORs and their associated CI for each categorical variable included in the multivariate analysis. As can be seen from the table, once the effects of other variables were controlled for, parental education, access to improved sanitation, place of residence, religious affiliation and membership to a credit association all lose their statistical significance. Moreover, the type of cooking fuel used by households, location of kitchen and access to electronic media showed a statistically significant association with childhood morbidity.

Age of the child, sources of drinking water, household wealth status and region of residence showed a significant impact on the incidence of childhood morbidity. Children aged between $0-17$ and 18-35 months showed a relatively higher incidence of these conditions compared to their older counterparts. Children belonging to households whose water source was other than pipe and who at the same time did not treat their drinking water were $86.0 \%$ ( $\mathrm{OR}=1.860,95 \%$ CI (1.269 to 2.728$)$ ) more likely to experience multiple health conditions than those belonging to households who had access to piped water and at the same time treated their drinking water. Similarly, children belonging to households using nontreated and piped drinking water had a $58.3 \%$ $(\mathrm{OR}=1.583,95 \%$ CI (1.051 to 2.382)) higher likelihood of experiencing multiple health conditions than those 
Table 1 Descriptive statistics of variables included in the analysis along with bivariate $\chi^{2}$ tests showing their association with child morbidity

\begin{tabular}{|c|c|c|c|c|c|}
\hline \multirow[b]{2}{*}{ Variable name } & \multirow[b]{2}{*}{ Levels } & \multicolumn{3}{|c|}{$\begin{array}{l}\text { Percentage of children suffering } \\
\text { from condition }\end{array}$} & \multirow{2}{*}{ Total } \\
\hline & & None & One & Two or more & \\
\hline \multirow[t]{3}{*}{ Child age ${ }^{\star \star *}$} & 0-17 months & 45.7 & 17.1 & 37.1 & $2141(28.4)$ \\
\hline & 18-35 months & 50.2 & 15.3 & 34.5 & 2029 (26.9) \\
\hline & $36-59$ months & 62.2 & 12.7 & 25.1 & $3380(44.8)$ \\
\hline \multirow[t]{2}{*}{ Sex of child } & Male & 54.3 & 14.2 & 31.5 & $3831(50.7)$ \\
\hline & Female & 54.3 & 15.1 & 30.6 & 3719 (49.3) \\
\hline \multirow[t]{7}{*}{ Division $^{\star * *}$} & Barisal & 53.5 & 13.4 & 33.1 & $411(5.4)$ \\
\hline & Sylhet & 54.8 & 14.7 & 30.5 & $591(7.8)$ \\
\hline & Khulna & 53.6 & 14.1 & 32.3 & 672 (8.9) \\
\hline & Rangpur & 58.2 & 12.0 & 29.9 & $828(11.0)$ \\
\hline & Rajshahi & 54.2 & 15.7 & 30.1 & $969(12.8)$ \\
\hline & Chittagong & 47.7 & 16.8 & 35.5 & $1730(22.9)$ \\
\hline & Dhaka & 58.1 & 13.9 & 28.0 & $2351(31.1)$ \\
\hline \multirow[t]{2}{*}{ Place of residence ${ }^{\star \star \star}$} & Rural & 53.7 & 14.5 & 32.0 & $5838(77.3)$ \\
\hline & Urban & 57.1 & 15.2 & 27.7 & $1712(22.7)$ \\
\hline \multirow[t]{2}{*}{ Mother's education ${ }^{\star * \star}$} & Below secondary & 54.3 & 13.4 & 32.3 & $3953(52.4)$ \\
\hline & Secondary+ & 54.3 & 16.1 & 29.6 & $3597(47.6)$ \\
\hline \multirow[t]{2}{*}{ Father's education** } & Below secondary & 53.5 & 14.1 & 32.4 & 4519 (59.9) \\
\hline & Secondary+ & 55.5 & 15.5 & 29.0 & $3031(40.1)$ \\
\hline \multirow[t]{2}{*}{ Access to electronic media ${ }^{\star \star \star}$} & No access & 55.1 & 12.1 & 32.8 & $3055(40.2)$ \\
\hline & Access & 53.8 & 16.4 & 29.9 & $4515(59.8)$ \\
\hline \multirow[t]{2}{*}{ Membership in microcredit * } & Not a member & 54.6 & 15.0 & 30.4 & $5584(74.0)$ \\
\hline & Member & 53.4 & 13.6 & 33.0 & $1966(26.0)$ \\
\hline \multirow[t]{2}{*}{ Mother's decision on child healthcare ${ }^{\star *}$} & No role & 55.8 & 14.0 & 30.2 & $4486(59.4)$ \\
\hline & Alone or jointly decide & 52.1 & 15.6 & 32.2 & $3065(40.6)$ \\
\hline \multirow[t]{2}{*}{ Religion** } & Muslim & 54.0 & 14.6 & 31.4 & $6909(91.5)$ \\
\hline & Others & 57.2 & 15.2 & 27.7 & $640(8.5)$ \\
\hline \multirow[t]{5}{*}{ Access to improved toilet facility ${ }^{\star \star *}$} & No sanitation & 53.1 & 13.0 & 33.9 & 369 (4.9) \\
\hline & Not improved-unshared & 54.2 & 13.8 & 32.1 & 3239 (42.9) \\
\hline & Not improved-shared & 51.9 & 15.2 & 32.9 & $1980(26.2)$ \\
\hline & Improved-shared & 58.9 & 15.2 & 25.9 & $723(9.6)$ \\
\hline & Improved-unshared & 56.2 & 16.4 & 27.5 & $1241(16.4)$ \\
\hline \multirow{4}{*}{$\begin{array}{l}\text { Source of drinking water and treatment } \\
\text { practice }^{\star \star \star}\end{array}$} & Non-piped untreated & 53.4 & 14.5 & 32.1 & 6483 (85.9) \\
\hline & Non-piped treated & 52.7 & 16.7 & 30.6 & $389(5.2)$ \\
\hline & Piped-untreated & 60.0 & 15.4 & 24.6 & $350(4.6)$ \\
\hline & Piped-treated & 68.4 & 14.0 & 17.6 & $329(4.4)$ \\
\hline \multirow[t]{2}{*}{ Type of cooking fuels ${ }^{\star \star *}$} & Non-cleaners & 53.6 & 14.2 & 32.2 & $6650(88.1)$ \\
\hline & Cleaners fuels & 59.9 & 17.8 & 22.3 & 900 (11.9) \\
\hline Household member & Smokes & 54.5 & 14.8 & 30.7 & 3949 (52.3) \\
\hline Smokes inside/outside & Does not smoke & 54.1 & 14.5 & 31.4 & $3601(47.7)$ \\
\hline \multirow{2}{*}{ Location of kitchen ${ }^{\star \star}$} & Within house & 51.4 & 13.5 & 35.1 & $1169(15.5)$ \\
\hline & Outside house & 54.8 & 14.9 & 30.3 & $6381(84.5)$ \\
\hline \multirow[t]{2}{*}{ children under five in household } & One child & 54.2 & 14.5 & 31.3 & $4503(59.6)$ \\
\hline & More than one child & 54.5 & 14.8 & 30.6 & $3048(40.4)$ \\
\hline \multirow[t]{3}{*}{ Wealth status ${ }^{\star \star *}$} & Poor & 53.7 & 12.5 & 33.7 & $2360(31.3)$ \\
\hline & Middle & 53.0 & 15.5 & 31.6 & 4099 (54.3) \\
\hline & Rich & 60.6 & 16.1 & 23.3 & $1091(14.5)$ \\
\hline Overall & & 54.3 & 14.7 & 31.0 & $7550(100)$ \\
\hline
\end{tabular}

Significance at ${ }^{*} p<0.10,{ }^{* *} p<0.05,{ }^{* * *} p<0.001$.

using treated and piped water. These differences remained significant even when only one condition was considered.

We also found a statistically significant association between incidence of childhood diseases and household wealth status, although the observed difference was statistically significant only for children who suffered multiple conditions. Thus, children belonging to the middle and poor household wealth status category were $34.9 \%(\mathrm{OR}=1.349,95 \% \mathrm{CI}(1.113$ to 1.636$))$ and $42.5 \%$ $(\mathrm{OR}=1.425,95 \%$ CI (1.130 to 1.796$))$ more likely to suffer from comorbidity than those from well-off 
Table 2 The ORs (confidence interval) with significance level for the studied covariates from multinomial logistic regression models for a single condition and comorbidity

\begin{tabular}{|c|c|c|c|}
\hline Variable name & Levels & $\begin{array}{l}\text { Single condition } \\
\text { OR (CI) }\end{array}$ & $\begin{array}{l}\text { Comorbidity } \\
\text { OR (CI) }\end{array}$ \\
\hline \multirow[t]{3}{*}{ Child age } & 0-17 months & $1.785(1.514 \text { to } 2.014)^{\star \star \star}$ & $1.985(1.746 \text { to } 2.255)^{\star * *}$ \\
\hline & 18-35 months & $1.466(1.241 \text { to } 1.732)^{\star \star \star}$ & $1.667(1.468 \text { to } 1.894)^{\star \star *}$ \\
\hline & 36-59 months & 1.000 & 1.000 \\
\hline \multirow[t]{7}{*}{ Division } & Barisal & 1.167 (0.835 to 1.632$)$ & $1.130(0.883$ to 1.448$)$ \\
\hline & Sylhet & $1.212(0.910$ to 1.614$)$ & 0.995 (0.794 to 1.245$)$ \\
\hline & Khulna & $1.096(0.838$ to 1.433$)$ & 1.170 (0.956 to 1.432$)$ \\
\hline & Rangpur & $0.888(0.682$ to 1.156$)$ & $0.960(0.793$ to 1.162$)$ \\
\hline & Rajshahi & 1.189 (0.948 to 1.492$)$ & 1.035 (0.866 to 1.238$)$ \\
\hline & Chittagong & $1.477(1.219 \text { to } 1.788)^{\star \star *}$ & $1.383(1.190 \text { to } 1.607)^{\star * *}$ \\
\hline & Dhaka & 1.000 & 1.000 \\
\hline \multirow[t]{2}{*}{ Place of residence } & Rural & $1.133(0.902$ to 1.374$)$ & 0.976 (0.830 to 1.148$)$ \\
\hline & Urban & 1.000 & 1.000 \\
\hline \multirow[t]{2}{*}{ Maternal education } & Below secondary & $0.893(0.755$ to 1.055$)$ & $1.032(0.907$ to 1.173$)$ \\
\hline & Secondary+ & 1.00 & 1.000 \\
\hline \multirow[t]{2}{*}{ Access to electronic media } & No access & $0.706(0.598 \text { to } 0.833)^{\star \star \star}$ & 0.926 (0.818 to 1.047$)$ \\
\hline & Access & 1.000 & 1.000 \\
\hline \multirow[t]{2}{*}{ Membership in microcredit } & Not a member & $1.031(0.877$ to 1.213$)$ & $0.895(0.793 \text { to } 1.009)^{\star}$ \\
\hline & Member & 1.000 & 1.000 \\
\hline \multirow[t]{2}{*}{ Religion } & Muslim & $1.034(0.811$ to 1.318$)$ & $1.252(1.029 \text { to } 1.522)^{*}$ \\
\hline & Others & 1.000 & 1.000 \\
\hline \multirow[t]{2}{*}{ Mother's decision on child healthcare } & No role & $0.866(0.754 \text { to } 0.995)^{\star \star}$ & 0.949 (0.853 to 1.057$)$ \\
\hline & Alone or jointly decide & 1.000 & 1.000 \\
\hline \multirow[t]{2}{*}{ Father's education } & Below secondary & $1.055(0.896$ to 1.243$)$ & 1.019 (0.898 to 1.157$)$ \\
\hline & Secondary+ & 1.000 & 1.000 \\
\hline \multirow[t]{5}{*}{ Access to improved toilet facility } & No sanitation & $1.076(0.722$ to 1.605$)$ & $1.052(0.781$ to 1.416$)$ \\
\hline & Not improved-unshared & $0.903(0.719$ to 1.133$)$ & $0.916(0.764$ to 1.099$)$ \\
\hline & Not improved-shared & $1.109(0.868$ to 1.416$)$ & $1.021(0.840$ to 1.241$)$ \\
\hline & Improved-shared & $0.866(0.650$ to 1.155$)$ & $0.905(0.714$ to 1.146$)$ \\
\hline & Improved-unshared & 1.000 & 1.000 \\
\hline \multirow{4}{*}{$\begin{array}{l}\text { Source of drinking water and treatment } \\
\text { practice }\end{array}$} & Non-piped untreated & $1.706(1.107 \text { to } 2.630)^{\star \star}$ & $1.860(1.269 \text { to } 2.728)^{\star \star}$ \\
\hline & Non-piped and treated & $1.803(1.139 \text { to } 2.854)^{\star *}$ & $1.945(1.300 \text { to } 2.910)^{\star \star}$ \\
\hline & Piped and untreated & 1.306 (0.820 to 2.080$)$ & $1.583(1.051 \text { to } 2.382)^{\star \star}$ \\
\hline & Piped and treated & 1.000 & 1.000 \\
\hline \multirow[t]{2}{*}{ Type of cooking fuels } & Non-cleaners & $0.642(0.473 \text { to } 0.870)^{\star \star}$ & $1.139(0.875$ to 1.484$)$ \\
\hline & Cleaners fuels & 1.000 & 1.000 \\
\hline \multirow[t]{2}{*}{ Location of kitchen } & Within house & 0.912 (0.739 to 1.126$)$ & $1.324(1.131 \text { to } 1.550)^{\star \star \star}$ \\
\hline & Outside house & 1.000 & 1.000 \\
\hline \multirow[t]{3}{*}{ Wealth status } & Poor & 1.156 (0.865 to 1.546$)$ & $1.425(1.130 \text { to } 1.796)^{\star \star}$ \\
\hline & Middle & $1.199(0.952 \text { to } 1.510)^{*}$ & $1.349(1.113 \text { to } 1.636)^{\star \star}$ \\
\hline & Rich & 1.000 & 1.000 \\
\hline Mothers age & Continuous & $1.005(0.992$ to 1.017$)$ & 0.994 (0.984 to 1.003$)$ \\
\hline Persons per room & Continuous & 0.990 (0.941 to 1.040$)$ & 0.997 (0.959 to 1.037$)$ \\
\hline
\end{tabular}

families. No significant difference in childhood morbidity was observed between administrative divisions in the country except for Chittagong division where the incidence of one condition and comorbidity were $47.7 \%$ and $38.3 \%$ more likely with respect to the reference region, Dhaka.

\section{DISCUSSION AND CONCLUSION}

Diarrhoea and ARI with its associated symptoms such as fever, cough and difficulty in breathing are among the most common forms of childhood morbidity, which lead to about one-fifth of child deaths globally. ${ }^{1}$ In Bangladesh alone, each year $45.7 \%$ of children suffer from these conditions, while about a third of these children are expected to succumb to death due to these conditions every year. This study was conceived with a broad objective of identifying the factors associated with childhood morbidity in the country so that policymakers, development partners and other relevant institutions can make use of the information for programming and planning purposes. 
To do so, we accessed one of the largest and most recent cross-sectional surveys conducted in the country in 2011. While the sample size of the survey and the presence of a large set of explanatory variables make the data attractive for the intended analysis, use of such data for analysing childhood illnesses, however, is not without limitations. First, given the cross-sectional nature of the source data, no consideration was made to measure seasonal variations in disease episode or their potential impact on the results of this study. The seasonal effects are minimised as the data were collected over a 6-month period covering both wet and dry seasons in the country. Second, our estimates on incidence of morbidity are based on women's self-report and not clinical examinations. However, given the short recall period, the bias is assumed to be minimal. We also assume that these biases are independent of the characteristics of women or of their children. In addition, although the 2011 data used in the study are the most recent data that the country has for such analysis, it is important to note that the current situation with respect to childhood morbidity may be different from what is reported in our study as situations may have changed in the past 4 years.

Within these caveats, we found evidence of a strong effect of age on incidence of morbidity in the country, a result which was consistent with previous studies in Bangladesh as well as in other countries such as DRC, Egypt, Ethiopia and Iraq. ${ }^{79} 101519$ This may be due to what is commonly known as the 'teething' effect, but specifically related to food supplements in the early stages of weaning that leads to diarrhoea. As reported, diarrhoea pathogens like enterotoxigenic Escherichia coli are commonly transmitted via weaning foods to young children as they get focally contaminated from impure water, unhygienic utensils or food handling. ${ }^{6}$ Moreover, as children start to crawl and begin exploring their immediate environment by themselves, they can easily pick up infection, especially if the environment around the house is not clean. However, as children get older, they develop immunity and also learn how to interact better with their surroundings, such as by avoiding unclean areas, and build their immune system, which reflects the decline in incidence of childhood diseases with age.

Incidence of childhood diseases was also observed to vary with household wealth status, although the relationship, as in previous studies, was found to be significant only for multiple than single health conditions. ${ }^{12}$ These differentials in rates of diseases by wealth status may be associated with both 'knowledge' and 'income' effects. The knowledge effect may have come from potential differences in childcare practices, such as boiling of drinking water, preparation of weaning foods or personal hygiene. On the contrary, households with better wealth status can also be expected to have the resources to afford better nutrition or live in houses made of better wall, flooring and roofing materials that can provide a comfortable living environment for children and reduce their risk of exposure to childhood diseases.
The analysis also shows that children from Chittagong division had about a $38.3 \%$ higher risk of experiencing multiple childhood conditions than those in the reference region, Dhaka division, which may be attributed to the environmental conditions that exist in this part of the country. The port city Chittagong gets heavy traffic each day, which may lead to increased risks of exposing infectious diseases to the children. The huge traffic condition in Chittagong also means that outdoor air pollution and other adverse environmental hazards are likely to be higher in Chittagong, and this in turn may be expected to put children in this region at an elevated risk of respiratory infection and diarrhoea diseases.

As mentioned previously, microcredit programmes in Bangladesh offer collateral-free credit to their members and also provide a package of support services such as essential healthcare, basic education and social awareness ${ }^{18}$ to poor people. Hence, in our study, we expected membership in such institutions to have a positive impact on the life of poor women and their children. ${ }^{25}$ However, in the context of reducing childhood morbidity, our result did not support this hypothesis, and there are potential reasons for this. First, given the diversity and number of these organisations, it may be the case that not all of them have the same package of services or even different branches of the same organisation treat their clients differently. Moreover, such organisations may be more motivated to loan related activities than the social awareness programmes.

Although parental education has shown an association with childhood morbidity in the bivariate analysis, both maternal and paternal education exhibited no significant association with morbidity once other variables were controlled for. This is similar to previous studies in the DRC $^{26}$ and Zimbabwe ${ }^{27}$ where maternal education also showed no significant association with childhood morbidity. Yet these studies are contrary to several findings in the literature on the importance of maternal education on child survival. ${ }^{28}$ Maternal education may have a greater effect on mortality than morbidity because educated mothers tend to reduce risk of exposure from a contaminated community environment or lack of safe water; however, their knowledge allows them to recognise the disease early and use healthcare facilities more effectively. ${ }^{27} 28$ There was also no association between incidence of childhood illness and the sex of the child, which suggests that parents in the survey are more likely to treat all their children in the same way and this may signal a cultural shift in gender equity at least among children in the country.

Hand washing is one of the interventions useful to reduce the incidence of diarrhoea and intra-household and inter-household transmission of influenza, ${ }^{29}{ }^{30}$ and it is therefore vital that future health promotion activities in the country lay emphasis on the importance of this practice. This is also consistent with the finding in this study regarding the importance of water treatment practices in reducing childhood morbidity in the country. 
However, our finding also suggests that for water treatment practice to be more effective the water itself should be sourced from the pipe. In Bangladesh, only 9\% of households had access to piped drinking water. Achieving universal coverage of such source, especially in rural settings, is quite challenging. Integrated policies in promoting hygienic water usage practice through motivation and logistic support can be helpful in reducing the incidence of diarrhoea, even when drinking water is sourced other than pipe. Well-developed awareness programmes involving both Government and nongovernment organisations can help to educate parents regarding hygienic feeding and rearing practices for their children. The programmes may include washing hands, using clean feeding bottles, feeding boiled water and providing an infection-free environment.

Acknowledgements The authors would like to acknowledge the Bangladesh Demographic and Health Survey (BDHS) team and all the participants during 2011 survey. The comments of the reviewers and the editor are gratefully acknowledged; they improved the flow, interpretation and understanding of the paper.

Contributors MMK and MMH conceptualised the study. The methodology was developed by MMK and MMH. Data interpretation and drafting of the paper were undertaken by MMK, MMH and RD. All authors made contributions to the overall manuscript and are responsible for the drafting of the manuscript.

Funding Center for Research and Action in Public Health.

Competing interests None declared.

Patient consent Obtained.

Provenance and peer review Not commissioned; externally peer reviewed.

Data sharing statement The study used data from the Bangladesh Demographic and Health Survey.

Open Access This is an Open Access article distributed in accordance with the Creative Commons Attribution Non Commercial (CC BY-NC 4.0) license, which permits others to distribute, remix, adapt, build upon this work noncommercially, and license their derivative works on different terms, provided the original work is properly cited and the use is non-commercial. See: http:// creativecommons.org/licenses/by-nc/4.0/

\section{REFERENCES}

1. Liu L, Johnson HL, Cousens S, et al., Child Heath Epidemiology Reference Group of WHO and UNICEF. Global, regional, and national causes of child mortality: an updated systematic analysis for 2010 with time trends since 2000. Lancet 2012;379:2151-61.

2. Institute for Health Metrics and Evaluation (IHME). Global Burden of Disease Compare. Estimates of under-five deaths. http://vizhub. healthdata.org/gbd-compare/ (accessed 19 Jun 2014).

3. Nandy S, Irving M, Gordon D, et al. Poverty, child under-nutrition and morbidity: new evidence from India. - Bull World Health Organ 2005;83:210-16.

4. Giashuddin MS, Kabir M, Hasan M. Economic disparity and child nutrition in Bangladesh. Indian J Pediatr 2005;72:481-7.

5. Balabanova D, Mills A, Conteh L, et al. Good health at low cost 25 years on: lessons for the future of health system strengthening. Lancet 2013;381:2118-33.
6. Black RE. Diarrheal diseases and child morbidity and mortality. Population and Development Review 1984:141-61.

7. Siziya S, Muula AS, Rudastsikira. Diarrhea and acute respiratory infections prevalence and risk factors among under-five children in Iraq 2000. Ital J Pediatrics 2009;35:8

8. Kamal MM, Richardson AM. Factors influencing acute respiratory infection of children in Bangladesh. Int J Stat 2013;8:239-50.

9. Kandala NB, Emina JB, Nzita PDK, et al. Diarrhea, acute respiratory infection, and fever among children in the Democratic Republic of Congo. Soc Sci Med 2009;68:1728-36.

10. El-Gilany AH, Hammad S. Epidemiology of diarrheal diseases among children under five years in Dakahlia, Egypt. East Mediterr Health J 2005;11:762-75.

11. Chen LC, Huq E, D'Souza S. Sex bias in the family allocation of food and health care in rural Bangladesh. Popul Dev Rev 1981;7:55-70

12. Henry FJ, Briend A, Fauveau V. et al. Gender and age differentials in risk factors for childhood malnutrition in Bangladesh. Ann Epidemiol 1993;3:382-6.

13. Microcredit Regulatory Authority, Gulfeshan Plaza, Sixth floor, Ramna, Dhaka 1217 Bangladesh. http://www.mra.gov.bd/index.php? option=com_content\&view=article\&id $=74 \&$ Itemid $=88$ (accessed 6 Sep 2014).

14. Zaman $\mathrm{K}$, Baqui $\mathrm{AH}$, Yunus, et al Acute respiratory infections in children: a community-based longitudinal study in rural Bangladesh. J Trop Pediatr 1997:43:133-7.

15. Kandala NB, Ji C, Stallard N, et al. Spatial analysis of risk factors for childhood morbidity in Nigeria. Am. J Trop Med Hyg 2007;77:770-9.

16. Ferdous F, Das SK, Ahmed S, et al. Diarrhea in slum children: observation a large diarrheal disease hospital in Dhaka, Bangladesh. Trop Med Int Health 2014;19:1170-6.

17. Ermisch J, Francesconi M. Family matters: impacts on family background on educational attainments. Economica 2001;68:137-56.

18. Hadi A. Integrating prevention of acute respiratory infections with micro-credit programme: experience of BRAC, Bangladesh. Public Health 2002;116:238-44.

19. Miherte TS, Alemie GA, Tefrra AS. Determinants of childhood diarrhea among under five children in Benishangul Gumuz Regional State, North West Ethiopia. BMC Pediatr 2014;14:102.

20. Thapa P, Basel P, Shrestha IB, et al. Household passive smoking and acute respiratory infection among under-five children attending Kanti Children's Hospital. J Nepal Health Res Counc 2013;25:151-4

21. Azad SMY, Bahauddin KM, Uddin MH, et al. Indoor air pollution and prevalence of acute respiratory infection among children in rural area of Bangladesh. J Biol Agricult Healthc 2014:4:60-71.

22. National Institute of Population Research and Training (NIPORT), Bangladesh Demographic and Health Survey. Mitra and Associates, Dhaka, Bangladesh and Calverton, Maryland, USA and ICF International. 2011.

23. The World Bank, Working for a World Free Poverty. http://data. worldbank.org/indicator/ NY.GDP.PCAP.CD (accessed 6 Sep 2014).

24. Lattin J, Carrol JD, Green PE. Analyzing multivariate data. Pacific Grove, CA: Thomson, 2003:474-95.

25. Schuler SR, Hashemi SM. Credit programs, women's empowerment, and contraceptive use in rural Bangladesh. Stud Fam Plann 1994:25:65-76.

26. Mock NB, Sellers TA, Abdoh AA, et al. Socioeconomic, environmental, demographic and behavioural factors associated with the occurrence of diarrhoea in young children in the Republic of Congo. Soc Sci Med 1993;36:807-16.

27. Root GPM. Sanitation, community environment and childhood diarrhoea in rural Zimbabwe. J Health Popul Nutr 2001;19:73-82.

28. Kinfu, Y. Maternal education and child survival in Addis Abab. Ethiop $J$ Health Dev 1992;6:11-15.

29. Black RE, Merson MH, Huq I, et al. Incidence of severity of rotavirus and Escherichia coli diarrhoea in rural Bangladesh: implications for vaccine development. Lancet 1981;317:141-3.

30. Ram PK, DiVita MA, Khatun-e-Jannat K, et al. Impact of intensive handwashing promotion on secondary household influenza-like illness in rural Bangladesh: findings from a randomized controlled trial. PLOS ONE 2015;10:e0125200. 